\title{
Indomethacin in rheumatoid arthritis: clinical effects, pharmacokinetics, and platelet studies in responders and nonresponders
}

\author{
N. BABER, L. D. C. HALlidAY, W. J. A. VAN DEN HEUVEL, \\ R. W. WALKER, R. SIBEON, J. P. KEENAN, T. LITTLER, \\ AND M. L'E. ORME
}

From the Departments of Pharmacology and Therapeutics and of Haematology, University of Liverpool, the Regional Rheumatology Unit, Leasowe Hospital, Moreton, Wirral, Merseyside, and Merck Sharpe anछt Dohme Ltd., Rahway, New Jersey, USA

SUMmARY Twenty patients with definite or classical rheumatoid arthritis entered and completed a sequential study of placebo for 1 week, oral indomethacin $25 \mathrm{mg} 3$ times a day for 3 weeks, and oral indomethacin $25 \mathrm{mg} 3$ times a day plus $100 \mathrm{mg}$ indomethacin suppository at night for 3 weeks: Twelve of the patients had previously been classified as responders and eight as nonresponders te indomethacin by an independent assessor. At the end of each period patients were assessed by $\circledast$ blind observer for duration of morning stiffness, pain score, digital joint size, grip strength, articulair index, analgesic tablet usage, and the patient's own overall global assessment and comparativs global assessment. In 8 of the 9 tests used responders improved on indomethacin in compariso with placebo, while nonresponders did not improve. There were no significant differences betweet responders and nonresponders in the plasma half-life, plasma clearance of indomethacin, protei禺 binding of indomethacin, or urinary excretion of free or conjugated indomethacin. There were $n \vec{S}$ significant differences between responders and nonresponders in the urinary excretion of 7HDP or in the platelet aggregation or platelet malonyldialdehyde production tests. In responders ther was a significant positive correlation between the plasma indomethacin concentration $(r=0 \cdot 44$. $\mathrm{P}<0.05$ ) and the percentage inhibition of malonyldialdehyde production by the platelets. Howeve in nonresponders this correlation, while significant $(P<0 \cdot 05)$, was negative $(r=-0 \cdot 498)$. Both foop responders and nonresponders there was a significant correlation between plasma indomethacin. concentration and the percentage reduction in 7HDPA. There was no correlation between the clinical response and the plasma concentration of indomethacin. There appears to be a biochemical difference between responders and nonresponders, which, while not necessarily causally linke $\$$ with the clinical response to indomethacin, is worthy of further study.

Indomethacin (Indocid) has been used in the treatment of rheumatoid arthritis for over 10 years. Many patients get a worthwhile beneficial effect from it but a significant proportion of patients are not improved (Bröll et al., 1976; Co-operating Clinics of the American Rheumatism Association, 1967). There is at present no clinical means of

Accepted for publication May 11, 1978

Correspondence to Dr M. L'E. Orme, Department of Pharmacology and Therapeutics, University of Liverpool, New Medical Building, Ashton Street, PO Box 147, Liverpool L69 3BX detecting those patients who will not respond to therapy with indomethacin, and possible reasons for failure to improve vary from a failure to take the capsules to the presence of severe side effects? This study was designed to compare a group of patients with rheumatoid arthritis who responded to indomethacin with a similar group of patients who had previously not improved with indomethacio therapy. In these patients the clinical and bios chemical response to indomethacin was observe $\mathbb{B}$ and the pharmacokinetics of indomethacin wete also studied. 
Methods

\section{PATIENTS}

A group of patients was selected for study who were judged by one of us (T.L.) to have either responded or not responded to a course of indomethacin over the previous 2 years. This information was noted but not revealed to the other investigators until the conclusion of the study. Twenty patients were selected, all of whom had classical or definite rheumatoid arthritis (Ropes et al., 1959). Twelve patients were initially categorised as responders and 8 as nonresponders to indomethacin and their details are shown in Table 1. Eight patients had previously had gold therapy and 4 had received corticosteroid therapy, though at least 5 years prior to the study.

\section{TRIAL DESIGN}

This was a single blind sequential study, the nature of which was explained to each patient and their informed consent obtained. Before the start of the study all anti-inflammatory drugs were stopped (indomethacin in 11 patients, ibuprofen in 5, and naproxen in 4). They were given matching indomethacin placebo capsules to be taken 3 times daily and a supply of paracetamol (16 patients) or Distalgesic (dextropropoxyphene and paracetamol) (4 patients). One week later they started active treatment with indomethacin $25 \mathrm{mg} 3$ times a day for a 3-week period. After this an indomethacin suppository (100 $\mathrm{mg}$ ) was given each night in addition to $25 \mathrm{mg} 3$ times a day by mouth for a further 3-week period. One patient had aesthetic objections to the suppository and was given instead a $100 \mathrm{mg}$ oral dose before sleep. For the final 3week period 17 patients were then given probenecid $0.5 \mathrm{~g}$ twice daily in addition to indomethacin $25 \mathrm{mg}$ 3 times a day by mouth as a means of increasing the plasma concentration of indomethacin. The results of the probenecid study are reported in detail elsewhere (Baber er al., 1978). Three patients developed side effects during the suppository period and were given placebo probenecid tablets.

Table 1 Patient characteristics

\begin{tabular}{lll}
\hline & Responders & Nonresponders \\
\hline Number & 12 & 8 \\
Age & $39-71$ & $51-67$ \\
& Mean 54.2 & Mean 56.9 \\
Sex & $3 \mathrm{M}: 9 \mathrm{~F}$ & $2 \mathrm{M}: 6 \mathrm{~F}$ \\
$\begin{array}{l}\text { Mean duration of disease } \\
\quad \text { (years) }\end{array}$ & $13 \cdot 3$ & $8 \cdot 6$ \\
$\begin{array}{l}\text { Previous surgery } \\
\text { Latex slide test, no. }\end{array}$ & 8 & 2 \\
$\begin{array}{l}\text { positive at 1/40 } \\
\text { Previous gold or }\end{array}$ & 6 & 3 \\
corticosteroid therapy & 7 & 5 \\
\hline
\end{tabular}

\section{CLINICAL ASSESSMENTS}

Each patient was seen at the end of the placebo period and at the end of each 3-week period of treatment. The final dose of indomethacin was taken at $0800 \mathrm{~h}$ and patients were assessed between $1100 \mathrm{~h}$ and $1200 \mathrm{~h}$ by one observer (L.H.) on each occasion. Clinical assessments included: (a) overall global assessment on a 5-point scale from very poor to very good; (b) comparative global assessment on a 5-point scale from much worse to much better compared to the previous visit; (c) the degree of pain was assessed by the patient on a vertical analogue scale being scored from 0 (no pain) to 9 (very severe pain); $(d)$ the duration of morning stiffness on a 5-point scale from 1 (more than 3 hours) to 5 (no stiffness); (e) grip strength (a mean of 3 measurements with each hand with a sphygmomanometer cuff inflated to $30 \mathrm{mmHg}$ ); $(f)$ digital joint size (mm) (Boardman and Hart, 1967) giving the sum of all 10 values; $(g)$ the articular index (Ritchie et al., 1968); and ( $h$ ) the number of paracetamol or Distalgesic tablets consumed.

At each visit the patient was weighed and questioned about the development of side effects, in particular headache and gastrointestinal irritation.

Blood samples were taken for the measurement of haemoglobin, white cell count, and erythrocyte sedimentation rate (ESR, Westergren). Blood samples were taken at $1100 \mathrm{~h}, 1200 \mathrm{~h}, 1400 \mathrm{~h}$, and $1600 \mathrm{~h}$. These blood samples were then centrifuged at $2000 \mathrm{rpm}$ for 10 minutes, and the plasma was pipetted off and stored at $-20^{\circ} \mathrm{C}$ prior to analysis of the indomethacin concentration. Plasma indomethacin concentrations were measured by a recently developed sensitive and specific gas-liquid chromatographic method using electron capture detection (Sibeon et al., 1978). Plasma albumin and glubulin concentrations were measured by AutoAnalyzer. The protein binding of indomethacin was measured in each patient by the method of equilibrium dialysis using the Dianorm (Fisons, MSE Ltd.) (Weder and Bickel, 1970). To patients' plasma $(1 \mathrm{ml})$ containing indomethacin $300 \mathrm{ng} / \mathrm{ml}$ was added $0.2 \mu \mathrm{Ci}$ of ${ }^{14} \mathrm{C}$ indomethacin (Merck Sharpe and Dohme), and $0.5 \mathrm{ml}$ of this plasma was then dialysed in duplicate against buffer. At least 1 plasma sample from each patient at each assessment was checked for the presence of salicylate by the method of Trinder (1954). Blood (20 ml) was also taken at $1200 \mathrm{~h}$ into citrate, and this blood was used within 60 minutes for the assay of malonyldialdehyde production by the platelets as described by Keenan et al. (1977).

A 24-hour urine collection was made on the day before each clinic visit. This urine was assayed for unchanged indomethacin content by the method of 
Sibeon et al. (1978) both before and after incubation with betaglucuronidase (Sigma Chemical Company) at $\mathrm{pH} 6 \cdot 5$. This enzyme converts indomethacin glucuronide back into unchanged indomethacin. The urinary output of $7 \alpha$-hydroxy-5, 11-diketotetranorprostane-1, 16 dioic acid (6HDPA) was also determined in 17 of the 20 patients. This metabolite is the main urinary metabolite of prostaglandins of the $E_{1}$ and $E_{2}$ series. 7 HDPA was measured by gas liquid chromatography linked to an LKB 9000 mass spectrometer using chemical ionisation (Walker et al., 1978).

\section{STATISTICAL METHODS}

The area under the plasma indomethacin concentration versus time curve (AUC) over a dosage interval ( 8 hours) was measured by the trapezoidal method. On at least 1 occasion in each patient blood was taken prior to dosing with indomethacin at $0800 \mathrm{~h}$ ( 0 hour), and the plasma indomethacin concentration was not significantly different from that at $1600 \mathrm{~h}$ ( 8 hours after closing). In all other cases, then, the 8-hour concentration was also used as the concentration at zero time. The steady state plasma indomethacin concentration $\left(\mathrm{C}_{\mathrm{SS}}\right)$ was calculated from the AUC:

$$
\mathrm{C}_{\mathrm{SS}}=\mathrm{AUC} / \gamma
$$

where $\gamma$ is the dosage interval, in this case 8 hours.

The plasma half life of indomethacin was calculated by least squares regression analysis of the terminal exponential phase of the plasma indomethacin concentration profile. The plasma clearance of indomethacin was calculated from the formula:

$$
\text { Plasma clearance }=\frac{F D}{\text { AUC }} \text { (Alexanderson, 1972), }
$$

where $F$ is the fraction of dose $D$ absorbed. $F$ is assumed to be one as shown by Alvan et al. (1975).

The changes in each clinical assessment were correlated with the plasma indomethacin concentrations using linear regression analysis. The changes in subjective assessments with treatments were analysed by the sign test, and changes in objective assessments (grip strength, Ritchie articular index, and digital joint size) were analysed by the Wilcoxon sign sum rank test. Comparisons of the effects of different treatments on pharmacokinetic measurements and the analgesic tablet counts were made by Student's $t$ test. Differences between chemical and biochemical analyses were also assessed by Student's $t$ test.

\section{Results}

All 20 patients completed the trial. Twelve patients had been classed as responders and 8 as non- responders to indomethacin prior to the study. The results are shown in Table 2 and the statisticar. analysis in Table 3.

INDIVIDUAL CLINICAL ASSESSMENTS Ritchie articular index. The scoring fell in bott treatment periods in comparison with placebo, bu布 this was statistically significant only for responders్ on oral plus rectal treatment.

Pain score. Oral therapy and oral plus rectait therapy reduced the pain scores for responders iff both oral and oral plus suppository periods. There were no significant differences in nonresponders.

Digital joint sizes. No significant changes were seeni

Duration of morning stiffness. Treatment reduced the duration of morning stiffness, and this reached statistical significance for responders on the $\operatorname{com}_{\bar{D}}$ bination of treatments.

Grip strength. Responders improved their grip strength significantly on both treatments in coms parison with placebo, while there was no significang change in nonresponders.

Consumption of analgesic tablets. There was significant reduction in the number of analgesie tablets consumed by responders in both oral an oral plus suppository periods $(P<0.05$ an $\Phi$ $\mathbf{P}<0.01$ respectively). There was no significant reduction in the number of analgesic tablets con? sumed by nonresponders. The difference between responders and nonresponders in the placeb $\bar{Q}^{2}$ period $(59 \cdot 3 \pm 16 \cdot 9$ and $36 \cdot 1 \pm 16 \cdot 0)$ is not sigo nificant $(\mathbf{P}>0 \cdot 1)$.

Comparative global assessment. This test was applicable only for placebo in comparison witl oral indomethacin because of the sequential natures of the trial. Only responders showed a significane improvement.

Current global assessment. Patients who wer尺 known responders preferred the combination treatment to placebo, but no other significant changes were noted.

\section{PATIENT COMMENTS}

The patients initially categorised as responders a preferred active indomethacin to placebo treatment but there was no further significant improvement if the suppository period. Patients initially categorise $\$$ as nonresponders, as a group showed no improve ment when active indomethacin was substituted fog 

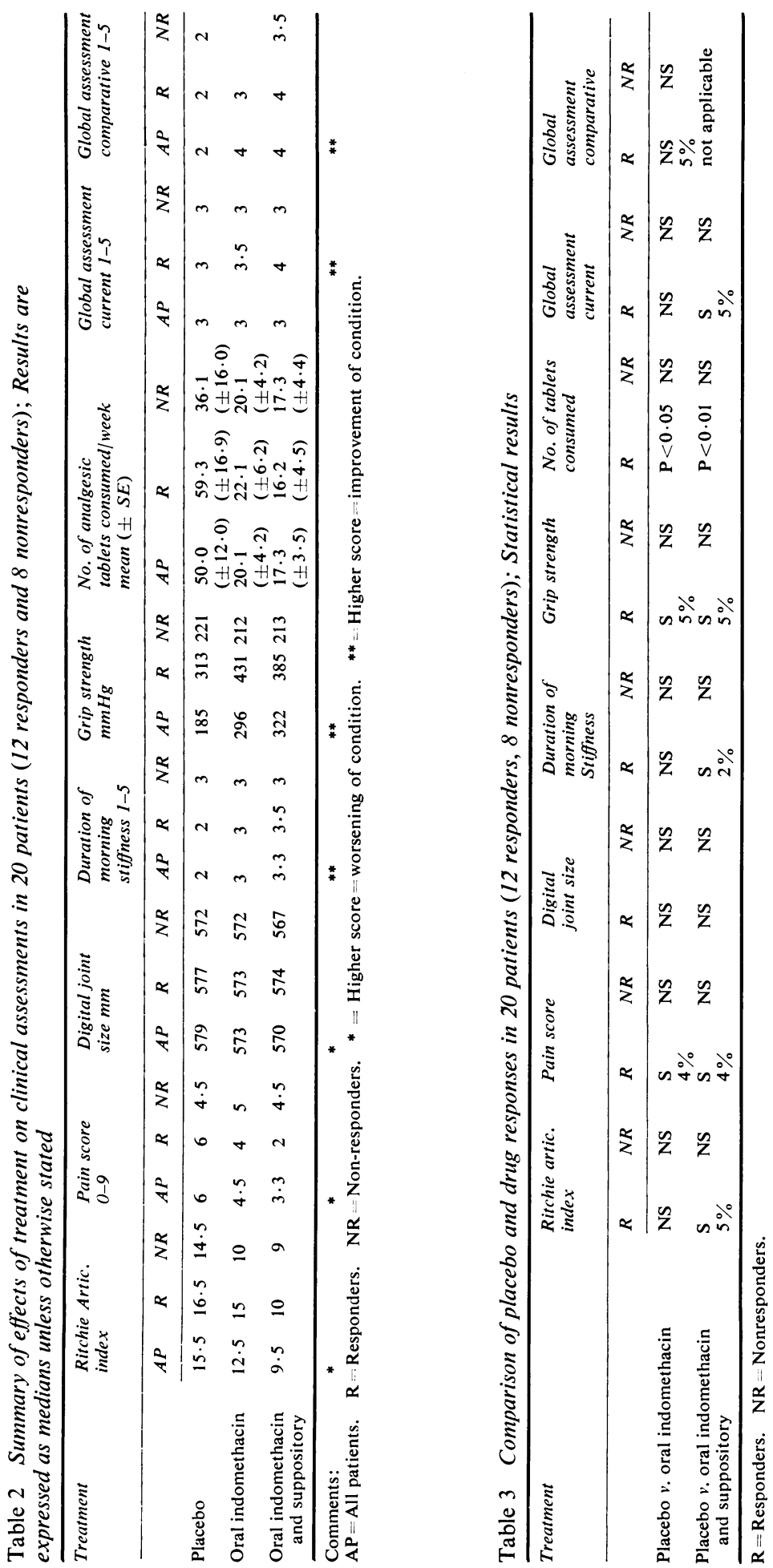
placebo. There were no significant changes in weight, haemoglobin, white cell count, or ESR during the study.

Side effects. The percentage of patients reporting side effects is given in Table 4. There were more general complaints (which often included headache and gastrointestinal disorders) on treatment than placebo. A history of headaches was elicited more frequently in both responders and nonresponders on combined treatment than with oral indomethacin, though the percentage was higher for responders. Gastrointestinal symptoms were more frequent on placebo for both groups.

\section{PLASMA INDOMETHACIN CONCENTRATIONS}

The steady state plasma indomethacin concentration as calculated from the area under the curve (AUC) correlated well with the 4-hour plasma concentration (the mid dosage interval) $(\mathrm{r}=0.931, \mathrm{n}=60$, $\mathrm{P}<0.001)$.

The pharmacokinetic data are shown in Table 5. The mean plasma half of indomethacin was between $3 \cdot 5$ and $4 \cdot 1$ hours. There was no significant difference in plasma half life or AUC or plasma clearance of indomethacin between responders and nonresponders $(P>0 \cdot 1)$. The nonresponders to indomethacin failed to respond to the drug even though their plasma concentrations were not significantly different from those seen in the responders. In practice the concentration in nonresponders was slightly higher than that in responders. As expected, the AUC increased significantly $(P<0.01)$ when the dose of indomethacin was increased by the additiow of the suppository, but there were no significarift changes in plasma half life of plasma clearance with the larger dose.

\section{PROTEIN BINDING}

The mean plasma albumin concentration in re sponders was $4 \cdot 00 \pm 0 \cdot 29 \mathrm{~g} / 100 \mathrm{ml}(40 \pm 2 \cdot 9 \mathrm{~g} / \mathrm{P}$ (mean $\pm \mathrm{SD}$ ) and in responders $4 \cdot 2 \pm 0 \cdot 24 \mathrm{~g} / 100 \mathrm{n}$ f $(42 \pm 2 \cdot 4 \mathrm{~g} / \mathrm{l})$, while the mean plasma globulin corb centration was $3.50 \pm 0.57 \mathrm{~g} / 100 \mathrm{ml}(35 \pm 5.7 \mathrm{~g} / \mathrm{t}$ in responders and $3 \cdot 37 \pm 0 \cdot 32 \mathrm{~g} / 100 \mathrm{ml}(33 \cdot 7 \pm 3 \cdot g$ $\mathrm{g} / \mathrm{l}$ ) in nonresponders. These figures are not sigi nificantly different. There were no significan? differences in protein binding of indomethaciơ between responders and nonresponders.

\section{PLATELET STUDIES}

The results of these studies are shown in Figs $\stackrel{\circ}{P}$ and 2. Indomethacin produced a significant in hibition of platelet aggregation in all patients, an there were no significant differences between responders and nonresponders. Increasing the dose of indomethacin by the addition of the suppository did not cause a further significant inhibition of platelet aggregation (Fig. 1). Indomethacin als caused a significant inhibition of the platelet pro duction of malonyldialdehyde (see Fig. 2), thoug there were again no significant differences betwee responders and nonresponders. The increased dos of indomethacin did not result in any furthe significant inhibition of malonyldialdehyde pros duction.

Table 4 Numbers of patients reporting side effects (percentage given to brackets)

\begin{tabular}{|c|c|c|c|c|c|c|c|c|c|c|}
\hline & \multicolumn{4}{|c|}{ General complaints volunteered } & \multicolumn{3}{|c|}{ Headaches (elicited by questions) } & \multicolumn{3}{|c|}{$\begin{array}{l}\text { Gastrointestinal symptoms } \\
\text { (elicited by questions) }\end{array}$} \\
\hline \multirow{4}{*}{$\begin{array}{l}\text { Placebo } \\
\text { Oral } \\
\text { indomethacin } \\
\text { Oral } \\
\text { indomethacin } \\
\text { plus suppository }\end{array}$} & $A P$ & $\boldsymbol{R}$ & \multicolumn{2}{|c|}{$N R$} & $A P$ & $\boldsymbol{R}$ & $N R$ & $A P$ & $\boldsymbol{R}$ & $N R$ \\
\hline & $3(15)$ & $2(20)$ & \multicolumn{2}{|c|}{$1(13)$} & $3(65)$ & $2(20)$ & $1(13)$ & $2(10)$ & $2(25)$ & $0(0)$ \\
\hline & $12(60)$ & $7(58)$ & \multicolumn{2}{|c|}{$5(63)$} & $365)$ & $2(16)$ & $1(13)$ & $1(5)$ & $0(0)$ & $1(12)$ \\
\hline & $13(65)$ & $8(67)$ & \multicolumn{2}{|c|}{$5(63)$} & $7(35)$ & $5(42)$ & $2(27)$ & $1(5)$ & $1(8)$ & $0(0)$ \\
\hline \multicolumn{11}{|l|}{$\mathbf{A P}=\mathbf{A l l}$ patients. } \\
\hline & & \multicolumn{5}{|c|}{ Oral indomethacin } & \multicolumn{4}{|c|}{ Oral and rectal indomethacin } \\
\hline & & $A P$ & & $\boldsymbol{R}$ & & $N R$ & $\boldsymbol{A P}$ & $\boldsymbol{R}$ & & $N R$ \\
\hline \multirow{3}{*}{\multicolumn{2}{|c|}{$\begin{array}{l}\text { Plasma half life (hours) } \\
\text { Area under the curve } \\
\text { (ng/ml } \times \mathrm{hr} \text { ) } \\
\text { Plasma clearance } 1 / \mathrm{kg} / \mathrm{h} \\
\text { Steady State plasma } \\
\text { concentration } \mathrm{ng} / \mathrm{ml}\end{array}$}} & \multirow{2}{*}{\multicolumn{2}{|c|}{$\begin{array}{l}3.53( \pm 0.297) \\
2550( \pm 213) \\
0.207( \pm 0.04)\end{array}$}} & \multicolumn{2}{|c|}{$3 \cdot 14( \pm 0 \cdot 399)$} & $3.99( \pm 0.490)$ & $4.08( \pm 0.435)$ & \multicolumn{2}{|c|}{$3.47( \pm 0.386)$} & $4.78( \pm 0 \cdot 808)$ \\
\hline & & & & $\begin{array}{l}249 \\
0 \cdot 19\end{array}$ & $\begin{array}{l}=296 \\
\pm 0.034)\end{array}$ & $\begin{array}{l}2640( \pm 284) \\
0 \cdot 224( \pm 0 \cdot 018)\end{array}$ & $\begin{array}{l}3740( \pm 305) \\
0 \cdot 208( \pm 0.03)\end{array}$ & \multicolumn{2}{|c|}{$\begin{array}{l}3524( \pm 376) \\
0 \cdot 198( \pm 0 \cdot 044)\end{array}$} & $\begin{array}{l}4060( \pm 522) \\
0.229( \pm 0.045)\end{array}$ \\
\hline & & \multicolumn{2}{|c|}{$319( \pm 16 \cdot 8)$} & & $\pm 14 \cdot 9)$ & $330( \pm 19 \cdot 9)$ & $467( \pm 38 \cdot 1)$ & \multicolumn{2}{|c|}{$440( \pm 47 \cdot 1)$} & $507( \pm 65 \cdot 1)$ \\
\hline
\end{tabular}




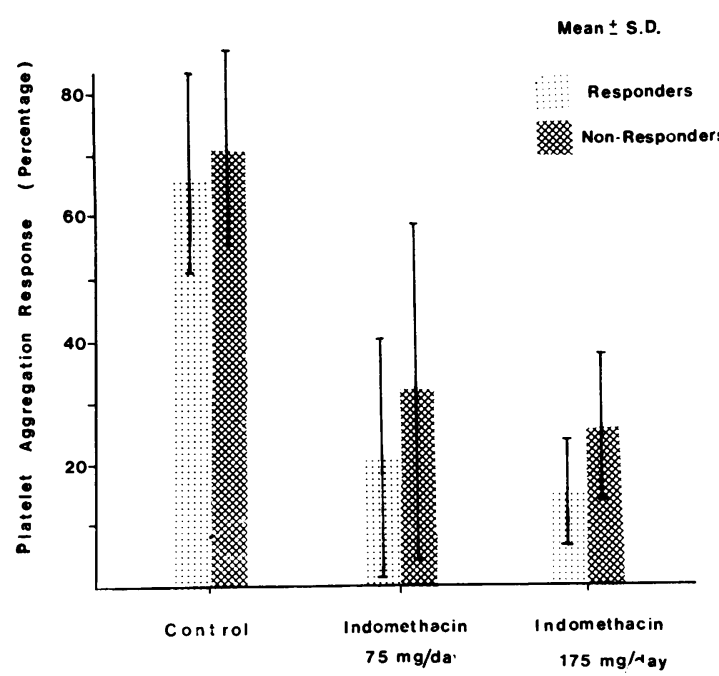

Fig. 1 Platelet aggregation response to collagen (expressed as a percentage of normal activity) in responders and nonresponders during the control period, at the end of 3-week treatment periods with oral indomethacin $25 \mathrm{mg} 3$ times a day and oral indomethacin $25 \mathrm{mg} 3$ times a day plus $100 \mathrm{mg}$ suppository at night. The results are expressed as the mean \pm standard deviation.

\section{URINARY DATA-INDOMETHACIN}

Table 6 shows the urinary excretion of indomethacin in both responders and nonresponders during both treatment periods. In the oral treatment period the excretion of unchanged indomethacin was $1380 \pm 196$ (mean $\pm \mathrm{SE}$ ) $\mu \mathrm{g} /$ day in responders and $1276 \pm 275$ $\mu \mathrm{g} /$ day in nonresponders. The excretion of unchanged indomethacin plus its glucuronide metabolite was $8235 \pm 1123 \mu \mathrm{g} /$ day in responders and

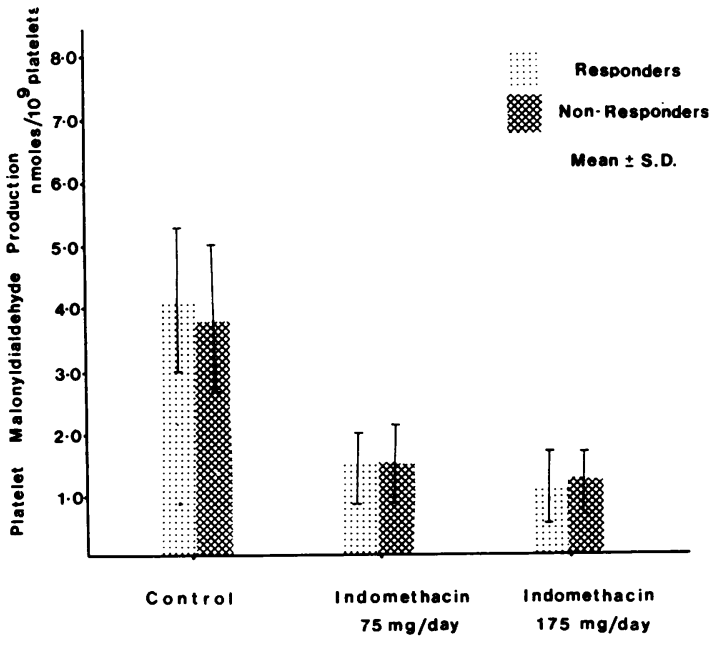

Fig. 2 Platelet malonyldialdehyde production (expressed as $n$ moles $/ 10^{9}$ platelets) in responders and nonresponders, during the control period and at the end of 3-week treatment periods with oral indomethacin $25 \mathrm{mg} 3$ times a day and then with oral indomethacin $25 \mathrm{mg} 3$ times a day plus $100 \mathrm{mg}$ suppository at night. The results are expressed as mean \pm standard deviation.

$9048 \pm 1107 \mu \mathrm{g} /$ day in nonresponders. During the suppository period the urinary excretion of unchanged indomethacin was $3571 \pm 668 \mu \mathrm{g} /$ day in responders and $3754 \pm 914 \mu \mathrm{g} /$ day in nonresponders. In no instance was the difference between responders and nonresponders significant.

The urinary excretion of 7HDPA is shown in Table 7. For technical reasons this assay was possible only in 10 of the 12 responder patients and

Table 6 Urinary excretion of indomethacin, $\S g /$ day; mean $\pm S D$

\begin{tabular}{|c|c|c|c|c|c|c|}
\hline \multirow[b]{3}{*}{ Patients } & \multicolumn{3}{|l|}{ Responders } & \multicolumn{3}{|c|}{ Nonresponders } \\
\hline & \multicolumn{2}{|c|}{ Oral indomethacin } & \multirow{2}{*}{$\begin{array}{l}\text { Oral }+ \\
\text { suppository } \\
\text { Unchanged }\end{array}$} & \multicolumn{2}{|c|}{ Oral indomethacin } & \multirow{2}{*}{$\begin{array}{l}\text { Oral }+ \\
\text { suppository } \\
\text { Unchanged }\end{array}$} \\
\hline & Unchanged & $\begin{array}{l}\text { Unchanged + } \\
\text { glucuronide } \\
\text { conjugate }\end{array}$ & & Unchanged & $\begin{array}{l}\text { Unchanged + } \\
\text { glucuronide } \\
\text { conjugate }\end{array}$ & \\
\hline 1 & 1264 & 7020 & 6144 & 538 & 9030 & 2780 \\
\hline 2 & 2566 & 12687 & 8133 & 748 & 7920 & 2402 \\
\hline 3 & 1205 & 5000 & 2035 & 243 & 7511 & 2608 \\
\hline 4 & 2354 & 13390 & 3414 & 2140 & 6104 & 4608 \\
\hline 5 & 2081 & 9520 & 4253 & 1631 & 9520 & 4316 \\
\hline 6 & 895 & 6750 & 2597 & 870 & 6700 & 1147 \\
\hline 7 & 754 & 5000 & 799 & 2338 & 9450 & 2622 \\
\hline 8 & 1225 & 12530 & 4230 & 1704 & 16146 & 9546 \\
\hline 9 & 238 & 638 & 1786 & & & \\
\hline 10 & 957 & 7250 & 584 & & & \\
\hline 11 & 1409 & 6936 & 6156 & & & \\
\hline 12 & 1613 & 12100 & 2730 & & & \\
\hline Mean & 1380 & 8235 & 3571 & 1276 & 9048 & 3754 \\
\hline$\pm \mathbf{S E}$ & 196 & \pm 1123 & \pm 668 & \pm 275 & \pm 1107 & \pm 914 \\
\hline Significance & & & & NS & NS & NS \\
\hline
\end{tabular}


Table 7 Urinary output of 7HDPA $\mu g /$ day; mean $\pm S E$

\begin{tabular}{llll}
\hline & $\begin{array}{l}\text { Responders } \\
(n=10)\end{array}$ & $\begin{array}{l}\text { Nonresponders } \\
(n=7)\end{array}$ & Significance \\
\hline $\begin{array}{l}\text { Control } \\
\text { Oral indomethacin } \\
\text { (\% reduction) }\end{array}$ & $\begin{array}{l}7 \cdot 52 \pm 1 \cdot 37 \\
\begin{array}{l}4.33 \pm 0.88 \\
(42.4)\end{array}\end{array}$ & $\begin{array}{l}4 \cdot 64 \pm 1 \cdot 06 \pm 3 \cdot 6 \\
(58 \cdot 0)\end{array}$ & NS \\
$\begin{array}{l}\text { Oral indomethacin } \\
\text { + suppository }\end{array}$ & $\begin{array}{l}3.03 \pm 0.54 \\
(59.7)\end{array}$ & $\begin{array}{l}3 \cdot 22 \pm 0.99 \\
(70.9)\end{array}$ & NS \\
\hline
\end{tabular}

7 of the 8 nonresponders. In both responders and nonresponders indomethacin significantly inhibited the urinary excretion of 7HDPA, but there were no significant differences between responders and nonresponders. Increasing the dose of indomethacin caused a further slight increase in the inhibition of 7HDPA excretion, but this was not statistically significant.

\section{CORRELATIONS WITH}

PLASMA INDOMETHACIN CONCENTRATIONS

Clinical effects. There were no significant correlations between the plasma concentrations of indomethacin and the degree of improvement in the various clinical tests.

Side effects. The mean steady-state plasma concentrations in the patients experiencing headache on indomethacin after oral plus suppository treatments was higher for both responders $(448 \mathrm{ng} / \mathrm{ml})$ and nonresponders $(457 \mathrm{ng} / \mathrm{ml})$ compared with the corresponding means for all patients in each subgroup $(307 \mathrm{ng} / \mathrm{ml}$ responders, $317 \mathrm{ng} / \mathrm{ml}$ nonresponders, $P<0.01)$. No relation was seen between gastrointestinal side effects and blood levels.

Biochemical effects. For the group of patients as a whole there was no significant correlation between either the inhibition of platelet aggregation or the inhibition of malonyldialdehyde production and the plasma indomethacin concentration. However, among the 12 responders there was a significant positive correlation between the percentage inhibition of malonyldialdehyde production and the plasma concentration of indomethacin $(r=0.441$, $n=24, P<0.05$; see Fig. 3 ). If the data from the probenecid period are included the correlation becomes closer, with $r=0.475,(P<0.01, n=36)$. Among the 8 nonresponders there was also a significant correlation between the percentage inhibition of malonyldialdehyde production and the plasma concentration of indomethacin, only here the correlation was negative $(r-=0 \cdot 498, n=16$,
$\mathrm{P}<0.05$; Fig. 4). If the data from the probeneci $\Phi$. period are included, the correlation coefficient improves to $-r=0 \cdot 504,(P<0 \cdot 01, n=24)$.

There was a significant positive correlation between the plasma concentration of indomethacif and the percentage inhibition of 7HDPA excretion

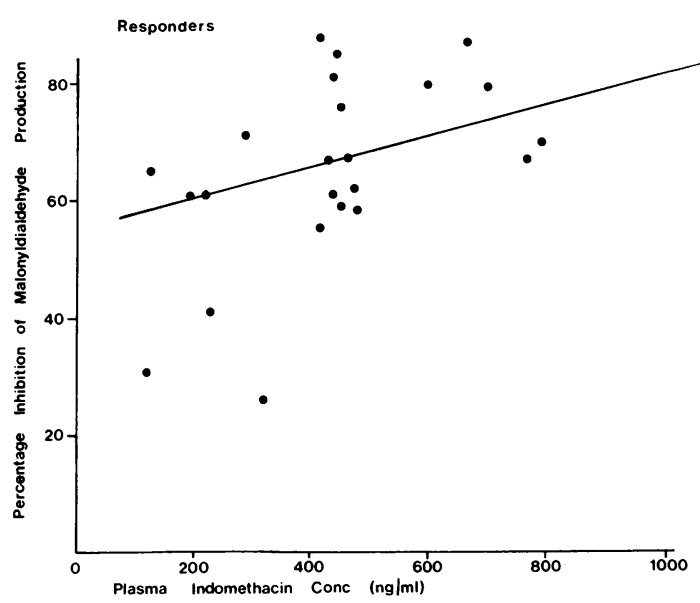

Fig. 3 Correlation between the percentage inhibition of platelet malonyldialdehyde production and the plasma concentration of indomethacin in 12 patients clinically responsive to indomethacin The data from both indomethacin treatment periods are included $(r=0.441$, $n=24, P<0.05, Y=56 \cdot 1 \pm 0.0248 X)$.

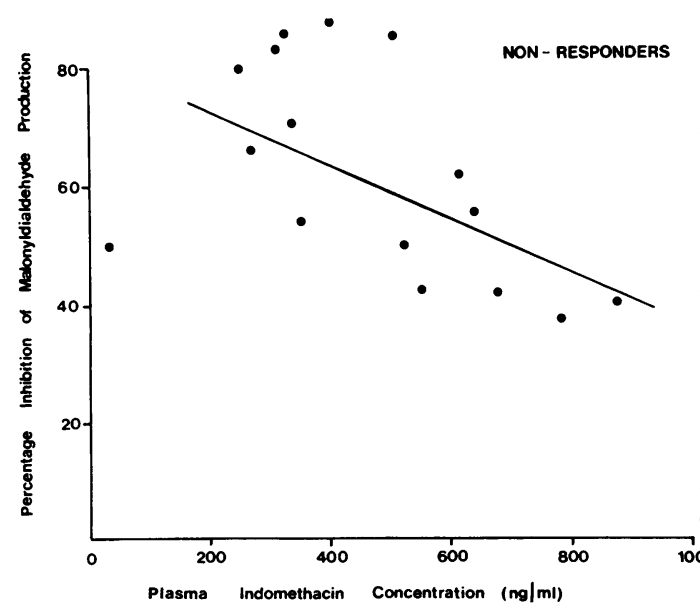

Fig. 4 Correlation between the percentage inhibition of platelet malonyldialdehyde production and the plasma concentration of indomethacin in 8 patients clinically unresponsive to indomethacin The data from both indomethacin treatment periods are included $(r=0.498$, $n=16, P<0.05, Y=80 \cdot 9-0.039 X)$. 


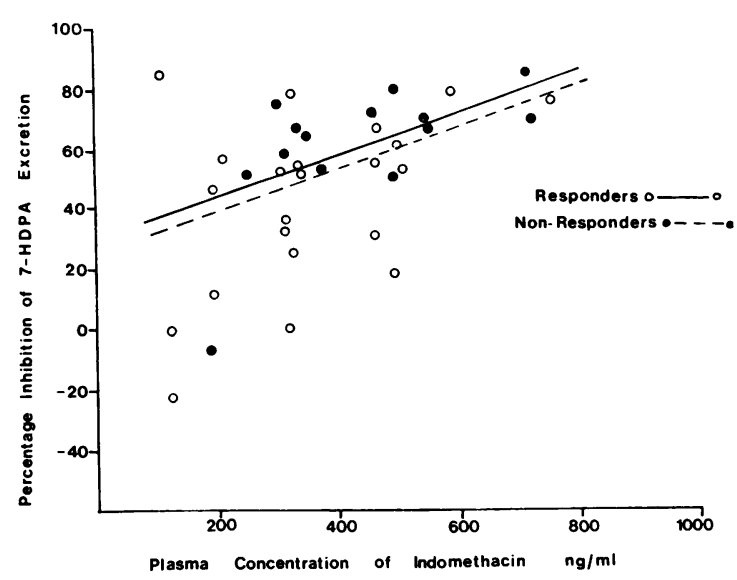

Fig. 5 Correlation between the percentage inhibition of urinary 7 HDPA excretion and the plasma concentration of indomethacin. The data from both treatment periods are included. For responders (10 patients) $r=0.437, n=20, P<0.05, Y=21.06+0.07 X$. For nonresponders (7 patients) $r=0.640, n=14, P<0.01$, $Y=25 \cdot 4 \pm 0.08 X$.

in both responders and nonresponders (Fig. 5). For responders the correlation coefficient was $r=0.437, n=20, P<0.05$, and for nonresponders $r=0.640, n=14, P<0.01$. The lines of identity are very similar in both groups (Fig. 5). For responders there was a significant correlation between the percentage change in 7HDPA excretion and the percentage change in platelet malonyldialdehyde production $(r=0.602, n=20, P<0.01)$, but there was no such correlation for nonresponders $(r=0 \cdot 078)$.

\section{Discussion}

This study has confirmed the initial observation of a failure to respond to indomethacin in the 8 nonresponsive patients. No clear reason emerges to explain the reason for the failure to respond. The 2 groups of patients were reasonably well matched with regard to sex and duration and severity of disease, though the responders had a slightly higher incidence of positive latex fixation tests than nonresponders. The plasma indomethacin concentrations were similar in both groups, indicating that initial failure to respond was unlikely to be due to a failure to take the drug. There were no significant differences in the pharmacokinetics of indomethacin or in the protein binding of indomethacin between responders and nonresponders. The failure to respond to indomethacin did not seem to be a question of the dose used, since the nonresponders showed no sign of improving even when the dose was increased to include an extra $100 \mathrm{mg}$ at night or when the plasma concentration was increased by the use of probenecid (Baber et al., 1978).

Failure to respond clinically to an anti-inflammatory drug is not unusual in the treatment of rheumatoid arthritis. Bröll et al. (1976) described patients who did not respond to indomethacin, and Huskisson et al. (1976) described patients who responded to fenoprofen or naproxen but not to ibuprofen. In many cases failure to respond has been taken to be due to failure to take the tablets, but in our study this has been shown not to be the reason.

The biochemical tests did not immediately suggest a difference between responders and nonresponders in that there were no clear-cut differences in either platelet malonyldialdehyde production or in the urinary excretion of 7HDPA. However, the correlations between the biochemical tests and the plasma indomethacin concentration appear to suggest a difference between responders and nonresponders. There is a positive correlation in both responders and nonresponders between the plasma indomethacin concentration and the urinary excretion of 7HDPA. This would suggest that indomethacin affects the synthesis of prostaglandin, $E_{1}$ and $E_{2}$ similarly in responders and nonresponders. However, while there is a similar positive correlation between the plasma indomethacin concentration and the percentage inhibition of platelet malonyldialdehyde production in responders, there is a significant negative correlation between these two variables in nonresponders. Thus, in nonresponders, as the plasma indomethacin concentration increases there is less inhibition of malonyldialdehyde production. Malonyldialdehyde is only one of the products of prostaglandin synthetase activity in the platelets, the other products being prostaglandin $\mathrm{E}_{1}$, thromboxane $\mathrm{A}_{2}$ and prostaglandin $F_{2 x}$. It is possible, therefore, that in nonresponders indomethacin may have differing effects on the various prostaglandin synthetase enzymes compared to responders. More detailed studies are in progress using ${ }^{14} \mathrm{C}$ arachidonic acid in platelet studies to investigate this possibility. This finding of a potential biochemical difference between responders and nonresponders does not mean that the 2 findings are necessarily causally related. Further studies are needed to confirm these observations and to see if the platelet malonyldialdehyde activity is linked with a clinical response to indomethacin. In this study, when individual nonresponding patients were examined, their platelet malonyldialdehyde response to indomethacin was of no value in predicting their individual clinical response to indomethacin. 
We are grateful to the Arthritis and Rheumatism Council for a grant to Dr T. R. Littler, to the Merseyside Regional Health Authority for a grant to purchase gas-chromatographic equipment, to Miss J. Singh for expert technical assistance, to $\mathrm{Mr} \mathrm{M}$. Ali for the protein binding studies, and to $\mathrm{Mr}$ M. Allison for help with the studies. We thank Merck Sharp and Dohme (USA) for financial help and for gifts of chemicals. M.O. was supported by the Wellcome Trust.

\section{References}

Alexanderson, B. (1972). Pharmacokinetics of desmethylimipramine and nortriptyline in man after single and multiple oral doses-a cross-over study. European Journal of Clinical Pharmacology, 5, 1-10.

Alvan, G., Orme, M., Bertilsson, L., Ekstrand, R., and Palmer, L. (1975). Pharmacokinetics of indomethacin in man. Clinical Pharmacology and Therapeutics, 18, 364-373.

Baber, N., Halliday, L., Sibeon, R., Littler, T., and Orme M. L'E. (1978). The interaction between indomethacin and probenecid. A clinical and pharmacokinetic study. Clinical Pharmacology and Therapeutics, 24, 298-309.

Boardman, P. L., and Hart, F. D. (1967). Clinical measurement of the anti-inflammatory effect of salicylates in rheumatoid arthritis. British Medical Journal, 4, 264-268.

Bröll, H., Tausch, G., and Eberl, R. (1976). Long-term treatment of arthritis with indomethacin. In Inflammatory Arthropathies, pp. 175-178. Edited by E. C. Huskisson and E. P. Velo. Excerpta Medica: Amsterdam and Oxford.

The Co-operating Clinics Committee of the American Rheumatism Association (1967). A three-month trial of indomethacin in rheumatoid arthritis with special reference to analysis and inference. Clinical Pharmacology and Therapeutics, 8, 11-37.
Huskisson, E. C., Woolf, D. L., Balme, H. W., Scott, J and Franklyn, S. (1976). Four new anti-inflammatorf drugs: responses and variations. British Medical Journo 1, 1048-1049.

Keenan, J. P., Wharton, J., Shepherd, A. J. N., and Bellingham, A. J. (1977). Defective lipid peroxidation 通 myeloproliferative disorders: A possible defect of pres staglandin synthesis. British Journal of Haematology, 35 275-283.

Ritchie, D. M., Boyle, J. A., McInnes, J. M., Jasani, M. Ko Dalakos, T. G., Grievson, P., and Buchanan, W. N. (1968) Clinical studies with an articular index for the assessment of joint tenderness in patients with rheumatoid arthritis Quarterly Journal of Medicine (New Series), 37, 393-406.

Ropes, M. W., Bennett, G. A., Cobb, S., Jacox, R., anep Jessor, R. A. (1959). Revision of diagnostic criteria for rheumatoid arthritis. Annals of the Rheumatic Diseases, 18 49-53.

Sibeon, R., Baber, N., Chan, K., Baty, D., and Ormỉ M. L'E. (1978). A quantitative gas liquid chromatographie method for the determination of indomethacin in bieo logical fluids. Journal of Chromatography, 153, 189-194.

Trinder, P. (1954). Rapid determination of salicylate biological fluids. Biochemical Journal, 57, 303-303.

Walker, R. W., Gruber, V. F., Pile, J., Yabumoto, Rosegay, A., Taub, D., Tempero, K. F., Orme, M. L'E Wolf, F. J. and Van den Heuvel, W. J. A. (1978). GLC-MS assay for $7 \alpha$-hydroxy-5, 11-diketotetronorprostane-1, dioic acid, the major human urinary metabolite of pre staglandins $\mathrm{E}_{1}$ and $\mathrm{E}_{2}$. Abstract to American Society Mass Spectrometry.

Weder, H. J., and Bickel, M. H. (1970). Interaction of drug with proteins. II. Experimental methods, treatment experimental data, and thermodynamics of binding reactions of thymoleptic drugs and model dyes. Journal of Pharmaceutical Sciences, 59, 1563-1569.

.

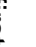

